\title{
Efficient Quantitative Analysis of Carboxyalkylpyrrole Ethanolamine Phospholipids: Elevated Levels in Sickle Cell Disease Blood
}

\author{
Junhong Guo ${ }^{1}$, Hua Wang ${ }^{1}$, Borys Hrinczenko², and Robert G. Salomon ${ }^{1},{ }^{*}$ \\ ${ }^{1}$ Department of Chemistry, Case Western Reserve University, Cleveland, Ohio, 44106, USA \\ ${ }^{2}$ Division of Hematology and Oncology, Michigan State University, East Lansing, MI 48824, USA
}

\begin{abstract}
$\gamma$-Hydroxy-a, $\beta$-unsaturated aldehydes, generated by oxidative damage of polyunsaturated phospholipids, form pyrrole derivatives that incorporate the ethanolamine phospholipid (EP) amino group such as 2-pentylpyrrole (PP)-EP and 2-( $\omega$-carboxyalkyl)pyrrole (CAP)-EP derivatives: 2-( $\omega$-carboxyethyl)-pyrrole (CEP)-EP, 2-( $\omega$-carboxypropyl)pyrrole (CPP)-EP, and 2( $\omega$-carboxyheptyl)pyrrole (CHP)-EP. Because EPs occur in vivo in various forms, a complex mixture of pyrrole-modified EPs with different molecular weights is expected to be generated. To provide a sensitive index of oxidative stress, all of the differences in mass related to the glycerophospholipid moieties were removed by releasing a single CAP-ethanolamine (ETN) or PP-ETN from each mixture by treatment with phospholipase D. Accurate quantization was achieved using the corresponding ethanolamine- $\mathrm{d}_{4}$ pyrroles as internal standards. The product mixture obtained by phospholipolysis of total blood phospholipids from sickle cell disease (SCD) patients, was analyzed by LC-MS/MS. The method was applied to measure CAP-EP and PP-EP levels in blood plasma from clinical monitoring of SCD patients. We found uniformly elevated blood levels of CEP-EP $(63.9 \pm 9.7 \mathrm{nM})$ similar to mean levels in blood from age-related macular degeneration (AMD) patients $(56.3 \pm 37.1 \mathrm{nM})$, two fold lower levels $(27.6 \pm 3.6 \mathrm{nM}, \mathrm{n}=5)$ were detected in plasma from SCD patients hospitalized to treat a sickle cell crisis, although mean levels remain higher than those $(12.1 \pm 10.5 \mathrm{nM})$ detected in blood from healthy controls. Plasma levels of CPP-EPs from SCD clinic patients were four-fold higher than those of SCD patients hospitalized to treat a sickle cell crisis $(45.1 \pm 10.9 \mathrm{nM}, \mathrm{n}=5$ versus $10.9 \pm 3.4 \mathrm{nM}, \mathrm{n}=6 ; \mathrm{p}<$ 0.002). PP-EP concentration in plasma from SCD clinic patients is nearly 4.8 -fold higher than its level in plasma samples from SCD patients hospitalized to treat a sickle cell crisis (7.06 \pm 4.05 vs $1.48 \pm 0.92 \mathrm{nM} ; \mathrm{p}<0.05)$. Because CAP-EPs promote angiogenesis and platelet activation, the elevated levels present in SCD blood can contribute to the hypercoaguability and vaso-occlusive events that are critical pathophysiologic features of SCD.
\end{abstract}

\section{Graphical abstract}

*To whom correspondence should be addressed at Department of Chemistry, Case Western Reserve University, Cleveland, Ohio 44106-7078; rgs@ case.edu, Phone: 216-368-2592. FAX: 216-368-3006. 


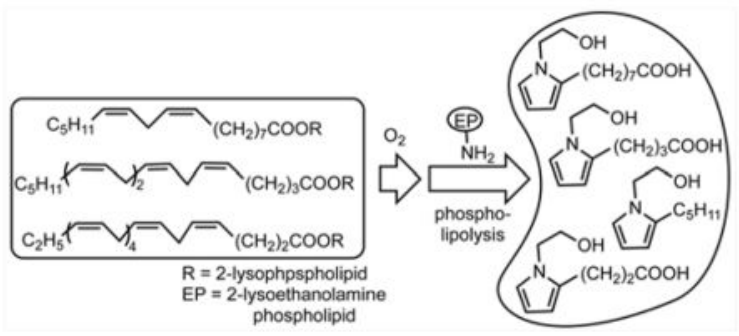

\section{INTRODUCTION}

\section{$\gamma$-Hydroxyalkenals are produced by oxidative fragmentation of PUFAs}

Phospholipids that contain polyunsaturated fatty acids (PUFAs), e.g., linoleic acid (LA), arachidonic acid (AA) or docosahexaenoic acid (DHA), are cellular targets of free radicalinduced oxidative damage ${ }^{1}$ that initially yields a variety of lipid hydroperoxides (Scheme 1). ${ }^{2}$ Fragmentation of these hydroperoxides generates oxidatively truncated aldehydes including $\gamma$-hydroxy-a, $\beta$-unsaturated aldehydes ( $\gamma$-hydroxyalkenals). ${ }^{3,4}$

\section{$\gamma$-Hydroxyalkenals form pyrroles that incorporate primary amino groups of biomolecules}

$\gamma$-Hydroxyalkenals are reactive electrophiles that modify biological nucleophiles such as proteins, DNA and ethanolamine phospholipids, to form adducts that have been demonstrated to be involved in several pathological processes. ${ }^{5} \gamma$-Hydroxyalkenal phospholipids containing 9-hydroxy-12-oxododec-10-enoic acid (HODA) or 5-hydroxy-8oxooct-6-enoic acid (HOOA) are restricted to diffuse laterally within membranes. However, phospholipids containing 4-hydroxy-7-oxohept-5-enoic acid (HOHA) are especially unstable, spontaneously $\left(\mathrm{t}_{1 / 2}=30 \mathrm{~min}\right.$ at $\left.37^{\circ} \mathrm{C}\right)$ releasing HOHA-lactone (Scheme 1). Nonesterified $\gamma$-hydroxyalkenals 4-hydroxy-2-nonenal (HNE) and 4-hydroxy-2-hexenal (4HHE $)^{2,6-8}$ as well as HOHA-lactone can diffuse from membranes and react with targets far from the site of their generation. ${ }^{9}$ Previously, we found that HNE, a lipid peroxidation product from oxidative fragmentation of LA or AA, forms 2-pentylpyrrole (PP) derivatives that incoporate the $\varepsilon$-amino group of protein lysine residues. ${ }^{2,10,11}$ In analogy with the chemistry of HNE, we subsequently showed that 4-HHE, derived from DHA, and phospholipids esterified with $\gamma$-hydroxy- $\alpha, \beta$-unsaturated aldehydes HODA, HOOA and HOHA, which are formed upon free radical-induced oxidation of phospholipids containing LA, AA, or DHA, respectively, generate the corresponding ethyl pyrrole, 2- $(\omega-$ carboxyheptyl)pyrrole (CHP), 2-( $\omega$-carboxy-propyl)pyrrole (CPP), and 2-( $\omega$ carboxyethyl)pyrrole (CEP) derivatives of proteins (Scheme 1). ${ }^{6,12,13}$

\section{Disease-related elevations of pyrrole epitope levels were first detected immunologically}

Immunohistochemistry and immunoassays with a panel of antibodies raised against protein derivatives of each of these pyrroles provide sensitive qualitative analyses of alkylpyrrole and carboxyalkylpyrrole derivatives produced in vivo. Using antibodies raised against PP modified proteins, we found that PP epitopes accumulate in the blood of individuals with atherosclerosis and in brain neurons of individuals with Alzheimer's disease. ${ }^{10,11}$

Immunoassay-based studies also revealed the presence of CHP and CPP epitopes in oxidized 
low-density lipoprotein. ${ }^{6}$ In addition, there is immunological evidence that mean levels of CHP epitopes are significantly elevated in renal failure and atherosclerosis patients compared with those in healthy volunteers. ${ }^{6} \mathrm{CEP}$ epitopes were found to be more abundant in age-related macular degeneration (AMD) than in normal Bruch's membrane/retinal pigmented epithelium/choroid tissues. ${ }^{14}$ The levels of CEP epitopes are elevated in human plasma from AMD donors relative to those in healthy donors. ${ }^{13}$

\section{Characterization of pyrrole-modified ethanolamine phospholipid levels in vivo}

CEP derivatives of proteins and peptides can stimulate choroidal neovascularization and promote wound healing and tumor growth in a Toll-like receptor (TLR)2-dependent manner. ${ }^{15,16}$ While the occurrence in vivo and biological activities of $\gamma$-hydroxy- $\alpha, \beta$ unsaturated aldehyde-derived pyrrole modifications of proteins has been well established, the extent of their adduction in vivo to ethanolamine phospholipids (EPs) remain poorly characterized. EPs account for $25 \%$ of mammalian phospholipids and are particularly enriched in the brain where the EPs comprise $45 \%$ of total phospholipids. ${ }^{17}$ Some ethanolamine phospholipid (EP) modifications by lipid peroxidation-derived aldehydes generated in vivo, such as the $\gamma$-ketoaldehyde isolevuglandins and the $\gamma$-hydroxyalkenals HNE and HOHA, have been reported recently. Levels of isolevuglandin-modified EPs are elevated in plasma of patients with AMD as well as in the liver of ethanol-fed mice. ${ }^{18}$ Analogous to the well-known reaction of lysyl $\varepsilon$-amino groups of proteins with these aldehydes, the primary amino group in EPs reacts with these aldehydes to generate pyrrole derivatives. ${ }^{4}{ }^{18-21}$ Recent evidence suggests that these EP pyrrole derivatives have important biological activities and may be involved in the pathogenesis of diseases associated with chronic oxidative stress. CEP-EPs derived from HOHA-PLs are not only present in human blood at 4.6-fold higher levels in AMD plasma than in normal plasma but also exhibit proangiogenic activity that is dependent on TLR 2 signaling similar to CEP-protein derivatives. ${ }^{21}$ We postulated that the analogous phospholipids containing the carboxyterminating $\gamma$-hydroxy- $\alpha, \beta$-unsaturated aldehydes HOOA and HODA would covalently modify the primary amino group of EPs to give the corresponding 2-( $\omega$ carboxyalkyl)pyrrole (CAP) derivatives, CPP from HOOA-PLs and CHP from HODA-PLs (Scheme 1).

\section{Simultaneous LC-MS/MS isotope dilution analysis of pyrrole-modified EP levels in vivo}

For the simultaneous measurement of both CAP- and PP- modified EPs in biological samples, there are many challenging problems. Firstly, multiple reactive aldehydes are generated from peroxidation of different PUFAs in vivo, which requires careful analysis with mass spectrometry. Liquid chromatography-tandem MS (LC-MS/MS) not only allows the use of internal isotopomer standards to correct for different sources of analytical variability but also the use of chromatography to separate different analytes to identify specific modifications of EPs, but at the same time allows the simultaneous measurement of various pyrrole-modified EPs. Secondly, isotope-labeled internal standard can be used to minimize variable sensitivity owing to any matrix effects for the biological samples. Because EPs are found in vivo in various forms, mainly 1,2-diacyl, 1-alkyl-2-acyl, and 1-vinyl-2-acyl forms, each of which can potentially differ in acyl chain length and unsaturation, a complex mixture of pyrrole-modified EPs with different molecular weights are expected to be 
generated. The amount of each species could be low, possibly below the lowest limit of mass spectrometric detection. To overcome this problem, we previously employed phospholipase A2 to convert the putative complex mixture of isolevuglandin-modified EPs into a much simpler mixture by hydrolyzing the sn-2 acyl chain releasing 2-lysophospholipid. ${ }^{18}$ However, this strategy only removes the differences in mass related to the sn-2 position. To provide an even more sensitive index of oxidative stress, phospholipase D (PLD) from Streptomyces chromofuscus can be used to remove all of the differences in mass related to the glycerophospholipid moieties by hydrolyzing various EP pyrrole derivatives to their corresponding modified ethanolamine (ETN) derivatives. This maneuver greatly simplifies the number of total masses that must be quantified ${ }^{21,22}$ releasing a single CAP-ETN or PPETN from each mixture of EPs (Scheme 2).

We now report that a sensitive quantitative simultaneous analysis of the various carboxyalkyl pyrrole derivatives of ethanolamine phospholipids can be achieved in a single LC-MS/MS experiment using isotope-labeled standards. The method is exemplified with an analysis of the levels of these pyrroles in blood from individuals with sickle cell disease (SCD).

Elevated blood levels were found during routine clinical monitoring of SCD patients and lower levels in patients during hospitalization to treat a sickle cell crisis.

\section{EXPERIMENTAL PROCEDURES}

\section{Materials}

PLD from Streptomyces sp. and Streptomyces chromofuscus were obtained from Enzo Life Sciences (Farmingdale, NY). Hank's balanced salt solution (HBSS) buffer was purchased from Thermo Scientific (Waltham, MA). Ethanol-1,1,2,2- $\mathrm{d}_{4}$-amine (ETN- $\mathrm{d}_{4}, 99$ atom \% D) was purchased from $\mathrm{C} / \mathrm{D} / \mathrm{N}$ Isotopes (Quebec, Canada). 6-[1,3]Dioxolan-2-yl-4-oxohexanoic acid-9H-fluoren-9-yl methyl ester (1), and 6-(1,3-dioxan-2-yl)-4-oxohexanoic acid (4) were provided by Dr. Li Hong. 7-(1,3-Dioxan-2-yl)-5-oxoheptanoic acid (5) and 11-(1,3dioxan-2-yl)-9-oxoundecanoic acid (6) were provided by Dr. Liang Xin. 4,7-Dioxoheptanoic acid $9 H$-fluoren-9-ylmethyl ester (DOHA-Fm, 2) was prepared as described previously. ${ }^{23}$ Details of the preparation of all the new compounds synthesized for this study are provided in the Supporting Information. All other chemicals and reagents were obtained from SigmaAldrich unless specified.

\section{General Methods}

Proton magnetic resonance ( ${ }^{1} \mathrm{H}$ NMR) spectra and carbon magnetic resonance $\left({ }^{13} \mathrm{C}\right.$ NMR) spectra were recorded on a Varian Inova AS400 spectrometer operating at $400 \mathrm{MHz}$ and 100 $\mathrm{MHz}$, respectively. Proton chemical shifts are reported as parts per million (ppm) on the $\delta$ scale relative to $\mathrm{CDCl}_{3}(\delta 7.26)$ or $\mathrm{CD}_{3} \mathrm{OD}(\delta 3.31) .{ }^{1} \mathrm{H}$ NMR spectral data are tabulated in terms of multiplicity of proton absorption (s, singlet; d, doublet; dd, doublet of doublet; $t$, triplet; q, quartet; m, multiplet; br, broad), coupling constants (Hz), number of protons. Carbon chemical shifts are reported relative to $\mathrm{CDCl}_{3}(\delta 77.0)$ or $\mathrm{CD}_{3} \mathrm{OD}(\delta 49.0)$. Flash chromatography was performed with ACS grade solvents from Fisher Scientific (Hanover Park, IL). $\mathrm{R}_{\mathrm{f}}$ values are quoted for TLC plates of thickness $0.25 \mathrm{~mm}$ from Whatman (Florham Park, NJ). The plates were visualized with iodine, dinitrophenylhydrazine or 
phosphomolybdic acid reagents. For all reactions performed in an inert atmosphere, argon was used unless otherwise specified.

\section{Extraction of lipids from blood plasma}

Clinically documented sickle cell disease blood was obtained from anonymized patients in the clinic and from hospitalized patients at the MetroHealth Medical Center. For this pilot study, blood was drawn during hospitalization and not at admission. Human blood samples from SCD patients were collected in $7 \mathrm{ml}$ vacutainer ${ }^{\mathrm{TM}}$ tubes (lavender top) containing EDTA $(10.5 \mathrm{mg})$. After incubating the tubes at room temperature for $30 \mathrm{~min}$, the upper yellow plasma layer was transferred into a $15 \mathrm{~mL}$ Falcon tube (Fisher Cat. \# 14-959-70C). BHT $(5 \mu \mathrm{L} / \mathrm{mL})$ and $10 \mu \mathrm{L} / \mathrm{mL}$ of protease inhibitor cocktail (Sigma, Cat.\# P8340) were added and mixed gently $5-6$ times by inversion of the tube. Remaining blood cells were removed by centrifugation at $2500 \mathrm{rpm}(1300 \times \mathrm{g})$ for $20-30 \mathrm{~min}$ at $4{ }^{\circ} \mathrm{C}$. Two $\mathrm{mL}$ of the supernatant was aliquoted into 8 vials (250 $\mu \mathrm{L} / \mathrm{vial})$ (Fisher Scientific Cat. No 02-681-343) with screw caps (Fisher Scientific Cat. No 02-681-358). The vials were flushed with argon, sealed with screw caps, and then quench-frozen in liquid nitrogen for $1 \mathrm{~min}$ and then stored at $-80{ }^{\circ} \mathrm{C}$. Phospholipids were extracted from the plasma by a modified Bligh and Dyer method. In brief, $750 \mu \mathrm{L}$ of chloroform/methanol $(1: 2, \mathrm{v} / \mathrm{v})$ containing $1 \mathrm{mM}$ BHT was added to the vial containing $200 \mu \mathrm{L}$ of plasma. The mixture was vortexed vigorously. Then $250 \mu \mathrm{L}$ of chloroform was added to the mixture, which was vortexed vigorously again. Aqueous sodium chloride solution $(250 \mu \mathrm{L}$ of $1.5 \%)$ was added and the resulting mixture was vortexed vigorously followed by centrifuging for $10 \mathrm{~min}$ at 3,000 RPM to give a threephase system (aqueous top, protein disk, organic bottom). The organic phase was withdrawn very carefully with a Pasteur pipette. The lipids were dried under a stream of dry nitrogen. The residue was stored under argon at $-80^{\circ} \mathrm{C}$ until analysis.

\section{Phospholipase D (Streptomyces chromofuscus) mediated hydrolysis of lipids}

The isolated phospholipids were hydrolyzed with PLD (Streptomyces chromofuscus) by the method described previously for hydrolysis of CEP-modified EPs. ${ }^{21}$ Briefly, lipids were resuspended in $50 \mu \mathrm{L}$ of methanol followed by the addition of $450 \mu \mathrm{L}$ of HBSS buffer supplemented with $5 \mathrm{mM} \mathrm{CaCl}_{2}$ and $0.1 \mathrm{mM}$ EDTA. Then the mixture was incubated at $37^{\circ} \mathrm{C}$ for 30 minutes and then sonicated for 10 minutes. Finally, small unilammelar vesicles (SUVs) were generated by passing the cloudy lipid mixture through a $0.1 \mu \mathrm{m}$ polycarbonate filter (17 times) for extrusion using an Avanti Mini-Extruder Set (Avanti Polar Lipids, Inc., Alabaster, AL). Then, 280 units of phospholipase D (Streptomyces chromofuscus) were added into the SUV solution and the resulting mixture was shaken under argon protection at $37^{\circ} \mathrm{C}$ overnight. Then the solvent was evaporated under a stream of dry nitrogen. The residue was stored at $-80^{\circ} \mathrm{C}$ under Ar and dissolved in $100 \mu \mathrm{L}$ of methanol and $20 \mu \mathrm{L}$ of this solution was injected when doing LC-MS/MS analysis.

\section{High performance liquid chromatography/mass spectrometry}

LC-ESI/MS/MS analysis of CAP-ETN and PP-ETN derivatives was performed on a Quattro Ultima triple-quadrupole mass spectrometer (Micromass, Wythenshawe, UK) equipped with a Waters Alliance 2690 HPLC system with an auto-injector (Waters, Milford, MA). The chromatographic separation was achieved using a Luna C18 column (150 $2.0 \mathrm{~mm}$ i.d. $5 \mu \mathrm{m}$, 
Phenomenex). The source and desolvation temperature were maintained at $120{ }^{\circ} \mathrm{C}$ and $250{ }^{\circ} \mathrm{C}$, respectively. The drying gas $\left(\mathrm{N}_{2}\right)$ and cone flow gas were kept at ca. $650 \mathrm{~L} / \mathrm{h}$ and 65 $\mathrm{L} / \mathrm{h}$, respectively. The multiplier was set at an absolute value of 600 . LC-MS/MS analysis was performed in the positive ion mode and the total run time was $45 \mathrm{~min}$. The mobile phase consisted of solvent A (HPLC grade water containing $0.1 \%$ formic acid) and solvent B (HPLC graded methanol containing $0.1 \%$ formic acid). The HPLC gradient steps were set as follows: $0-5 \mathrm{~min}$, isocratic at $5 \%$ solvent $\mathrm{B} ; 5-25 \mathrm{~min}$, linear gradient from 5 to $100 \%$ solvent B; $25-35 \mathrm{~min}$, isocratic at $100 \%$ solvent B; 35-45 min, isocratic at 5\% solvent B. The flow rate employed was $200 \mu \mathrm{L} / \mathrm{min}$.

Optimized parameters for detection of CAP-ETN and PP-ETN derivatives were determined with authentic samples. MS scans at $\mathrm{m} / \mathrm{z} 30-330$ were obtained for standard compounds. For multiple reaction monitoring experiments, argon was used as collision gas at a pressure of 5 psi. The optimum collision energy and other parameters were determined for each individual analyte as summarized in tables S1 and S2.

\section{Statistical Analysis}

Statistical analyses were performed by using Student's $t$ test. A P value $<0.05$ is considered as statistically significant. Representative p-values in figures include "NS"-not significant, “*” $<<0.05$, “**” $p<0.002$, “***” $p<0.0001$. Data are presented as mean \pm SD.

\section{RESULTS}

\section{Simultaneous quantitative analysis of CAP-EPs and PP-EPs in biological samples}

As summarized in Scheme 3, total phospholipids isolated from biological samples by a modified Bligh \& Dyer method, were prepared for phospholipolysis by conversion into small unilamellar vesicles (SUVs) by extrusion. After addition of internal standards CAPETN- $\mathrm{d}_{4}$ and PP-ETN- $\mathrm{d}_{4}$, phospholipase D from Streptomyces chromofuscus was added to catalyze the release of CAP-ETN and PP-ETN. The resulting product mixture was then analyzed by injection into the LC-MS/MS. In a control experiment, quantitative release of CEP-ETN from CEP-DPPE was observed after incubation for $1 \mathrm{~h}$ (data not shown).

Nevertheless, for phospholipids extracted from biological samples, incubation with PLD was always allowed to proceed overnight.

\section{Syntheses of CAP and PP derivatives of ETN and DPPE}

All CAP derivatives of ETN and deuterated ETN as well as of DPPEs were prepared by unambiguous chemical syntheses. The non-deuterated authentic CEP-ETN (3a) and deuterated authentic internal standard CEP-ETN- $\mathrm{d}_{4}(\mathbf{3 b})$ were synthesized as described previously. ${ }^{21}$ Briefly, the propylene acetal group of 6-[1,3]dioxolan-2-yl-4-oxo-hexanoic acid-9H-fluoren-9-yl-methyl ester (1) prepared by Dr. Li Hong in Dr. Salomon's lab was removed by treatment with aqueous acetic acid to give the 9H-fluoren-9-ylmethyl ester of 4,7-dioxo-heptanoic acid (DOHA-Fm, 2). Finally, CEP-ETN (3a) and CEP-ETN-d 4 (3b) were generated by the reaction of 2 with ETN or ethanol-1,1,2,2- $\mathrm{d}_{4}$-amine $\left(E T N-\mathrm{d}_{4}\right)$ through a Paal-Knorr reaction followed by the removal of the Fm ester by 1,8diazabicyclo[5.4.0]undec-7-ene (Scheme 4). 
For other authentic CAP-ETN derivatives (CPP-ETN and CHP-ETN) and deuterated CAPETN derivatives (CPP-ETN- $\mathrm{d}_{4}$ and CHP-ETN- $\mathrm{d}_{4}$ ) as well as authentic CAP-DPPE derivatives (CEP-DPPE, CPP-DPPE and CPP-DPPE), there was no need to protect the carboxyl group to obtain a high level of modification. In brief, the propylene acetal group of the dioxolane-protected carboxylic acid provided by Dr. Li Hong in Dr. Salomon's lab was removed by treatment with aqueous acetic acid to give the corresponding $\gamma$-keto aldehyde carboxylic acids that delivered carboxyalkylpyrrole derivatives by Paal-Knorr synthesis (Scheme 5).

For the synthesis of non-deuterated authentic PP-ETN and deuterated authentic internal standard PP-ETN-D 4 , the Paal-Knorr synthesis was successfully applied to the generation of PP derivatives from 4-oxononanal. 4-Oxononanal was prepared by a method published elsewhere with minor modification. ${ }^{24}$ Briefly, the commercially available starting material $\gamma$-nonalactone was first reduced by $\mathrm{LiAlH}_{4}$ to nonane-1,4-diol, which was then converted to 4-oxononanal through Swern oxidation. (Scheme 6).

\section{Test the hypothesis that pyrrole modified EPs are substrates for PLD from Streptomyces chromofuscus}

Although PLD is an efficient lipase of levuglandin and isolevuglandin derivatives of EPs (also referred to as $\gamma$-KA-EPs) and CEP-EPs, ${ }^{21,} 22$ whether PLD can hydrolyze other pyrrole modified EPs was not known. Therefore, the ability of PLD (Streptomyces chromofuscus) to catalyze the hydrolysis of pyrrole derivatives of EP was evaluated by treatment authentic CAP-DPPE with PLD from Streptomyces chromofuscus followed by analysis by LC-MS in the negative ion mode. As shown in Figure 1A-C, significant peaks were observed in the selected ion chromatograms (SICs) corresponding to CAP-ETNs after hydrolysis of CAPDPPEs catalyzed by PLD from Streptomyces chromofuscus, confirming that CAP-DPPEs are substrates for PLD (Streptomyces chromofuscus). To verify that the CAP-ETN was produced by PLD-catalyzed hydrolysis of CAP-DPPE, the hydrolysis product from CHPDPPE without PLD (Streptomyces chromofuscus) treatment was also studied by LC-MS as a representative. As shown in Figure 1D, no peak corresponding to CHP-ETN was observed in the SIC of the reaction product mixture from hydrolysis of CHP-DPPE in the absence of PLD.

\section{LC-MS/MS analysis of authentic CAP and PP derivatives of ETN and deuterated ETN}

For the analysis of CAP and PP derivatives of EPs in biological samples by reverse phase HPLC/ESI/MS/MS using multiple reaction monitoring (MRM), a MRM method was developed based on the collision induced dissociation (CID) spectra of $[\mathrm{M}+\mathrm{H}]^{+}$of the parent ion for authentic CAP and PP derivatives of ETN and deuterated ETN in the positive ion mode. Figures S1-S4 show representative CID spectra of authentic CAP and PP derivatives of ETN and deuterated ETN. MRM of the transitions $184.3 \rightarrow 124.2,188.4 \rightarrow 128.2$, $198.4 \rightarrow 162.5,202.4 \rightarrow 166.4,254.3 \rightarrow 124.1,258.4 \rightarrow 128.1,182.4 \rightarrow 94.1$ and 186.4 $\rightarrow 98.2$ were then used to analyze CEP-ETN (3a), CEP-ETN-d 4 (3b), CPP-ETN (10a), CPP-ETN-d ${ }_{4}(\mathbf{1 0 b})$, CHP-ETN (11a), CHP-ETN-d ${ }_{4}(\mathbf{1 1 b})$, PP-ETN (18a) and PP-ETN-d 4 (18b), respectively. Therefore, these eight MRM transitions were set to monitor the LCMS/MS of a mixture of all eight authentic standards. As shown in Figure 2, there are strong 
signals for each channel in the MRM. Signals for the CEP, CPP, CHP and PP derivatives are well separated by LC. Consequently, this LC-MS/MS method can be used for the simultaneous analysis of all three CAP-ETNs and PP-ETN in biological samples.

\section{LC-MS/MS demonstration that CAP and PP derivatives of EPs are present in human plasma}

Sickle cell disease (SCD) is a class of hemoglobinopathy in humans clinically characterized by chronic hemolysis, inflammation and vaso-occlusion, causing a decreased quality of life and life expectancy. ${ }^{25}$ Chronically elevated oxidative stress is an important feature of SCD and might play a significant role in the pathophysiology of a cascade of SCD-related debilitating conditions. ${ }^{25-27}$ Despite the mounting evidence of oxidative stress in $\mathrm{SCD}^{28}$, there is still no practical biomarker for determining the degree of oxidative stress and disease severity in SCD. ${ }^{25,26}$ Since CAP and PP derivatives have been measured immunologically in human blood plasma, we anticipated that CAP and PP derivatives of EPs exist in human plasma and might serve as biomarkers indicative of the disease state in SCD.

Based on the workflow developed for detection of CAP and PP derivatives of EPs in biological samples (Scheme 3), a pilot study was launched to examine their presence in blood plasma samples from routine clinical monitoring of SCD patients and hospitalized patients during a sickle cell crisis. In brief, phospholipids were first extracted from $200 \mu \mathrm{L}$ of human plasma samples from hospitalized and clinic patients with SCD by a modified Bligh \& Dyer method. Then lipid extracts were prepared as SUV followed by the addition of a fixed amount of each of the internal standards, CAP-ETN-d $\mathrm{d}_{4}$ and PP-ETN- $\mathrm{d}_{4}(0.01 \mathrm{nmol})$ and the mixtures were then hydrolyzed by 280 units of PLD (Streptomyces chromofuscus). The amounts of CAP-ETN and PP-ETN released from blood lipids in the hydrolysis reaction product mixtures were determined by the LC-MS/MS methods described above.

To determine the linearity and sensitivity of the assay for measurement of CAP-ETN and PP-ETN, calibration curves were constructed with authentic CAP-ETN and PP-ETN in 200 $\mu \mathrm{L}$ of HBSS buffer in the concentration range from 4 to $80 \mathrm{nM}$ spiked with a fixed amount of each of internal standards, CAP-ETN- $\mathrm{d}_{4}$ and PP-ETN- $\mathrm{d}_{4}(0.01 \mathrm{nmol})$. The peak area ratio of CAP-ETN or PP-ETN to CAP-ETN- $\mathrm{d}_{4}$ or PP-ETN- $\mathrm{d}_{4}$ from the LC-MS/MS analysis was plotted against calibrator concentrations to generate the corresponding curves and equations as shown in Figure S5A-D. These equations were then used to calculate the measured amount of CAP-ETN and PP-ETN in the hydrolysis reaction product mixtures from human blood plasma samples. For human plasma samples, the CAP or PP-EP concentration was calculated as follows:

$[$ CAP- EP or PP- EP $]=\left[\right.$ Area $($ CAP- EP or PP- ETN $) /$ Area $\left(C A P-E P-d_{4}\right.$ or PP- ETN-d $\left.d_{4}\right)-$ Intercept $] \times 1000 / 2 S l o p e ~(n M)$

The LC-MS/MS analysis of lipid extracts after treatment with PLD revealed the presence of all CAP-EP and PP-EP derivatives in human blood plasma. Representative LC-MS/MS chromatograms of CAP-ETN and PP-ETN detected in PLD-hydrolyzed lipid extracts from human blood plasma samples from hospitalized and clinic patients with SCD are shown in Figures 3 and 4. 


\section{DISCUSSION}

\section{Blood levels of CEP-EP, CPP-EP and PP-EP are massively elevated in SCD}

In a clinical pilot study, we applied an LC-MS/MS analysis to simultaneously determine CAP-EP and PP-EP levels in blood plasma from routine clinical monitoring of SCD patients $(\mathrm{SC}-\mathrm{C}, \mathrm{n}=5)$ and from SCD patients hospitalized to treat a sickle cell crisis $(\mathrm{SC}-\mathrm{H}, \mathrm{n}=6)$. The results are summarized in Table 1. Uniformly elevated blood levels of CEP-EP (63.9 $\pm 9.7 \mathrm{nM}$ ) are found during routine clinical monitoring of SCD patients. Although mean CEP-EP levels are similarly elevated in blood from AMD patients $(56.3 \pm 37.1 \mathrm{nM})$ compared to individuals with no disease $(12.1 \pm 10.5 \mathrm{nM})$, there is much greater variation in the levels detected in AMD compared to SCD. One factor that could account for this variability is the localization in the eye of the oxidative injury in AMD. To be detected in the blood, CEP-EPs or their precursors must cross the blood-retina barrier. There may be significant differences in the disease-related permeability of that barrier. As shown in Figure $5 \mathrm{~A}$ and Table 1, two fold lower levels $(\mathrm{P}<0.002)$ of CEP-EPs $(27.6 \pm 3.6 \mathrm{nM}, \mathrm{n}=5)$ were detected in plasma from SCD patients hospitalized to treat a sickle cell crisis. It is important to emphasize that all the hospitalized patients had their blood drawn during hospitalization and not at admission and had received multiple blood transfusions, significant amounts of intravenous fluids for rehydration, and strong narcotics for pain control. This quickly attenuated their pain crisis presumably limiting further oxidative damage. The dilution of their plasma volume by these therapeutic approaches most likely influenced our results, giving lower marker values than in non-hospitalized patients not in a pain crisis. Further studies will be needed to obtain a blood sample from each sickle cell disease patient in a pain crisis at admission just prior to any therapeutic intervention. The present pilot study did not assess the peak of their pain crisis, which most likely would be at admission, but was representative of a successful strategy that is currently used in hospitalized sickle cell patients to ameliorate symptoms. This pilot study suggests, but by no means establishes, that therapeutic measures have some efficacy in lowering CEP-EP levels, although mean levels remain higher than those $(12.1 \pm 10.5 \mathrm{nM})$ detected in blood from healthy controls in a previous study of CEP-EP levels in blood from AMD patients. A much larger clinical study is required to assess the influences of many other factors, e.g., age, smoking, and other coexisting diseases like cardiovascular disease, on levels of CAP-EPs in sickle cell disease blood.

Similarly, as shown in Figure 5B and Table 1, plasma levels of CPP-EPs from SCD clinic patients were four-fold higher than those of SCD patients hospitalized to treat a sickle cell crisis $(45.1 \pm 10.9$ versus $10.9 \pm 3.4 \mathrm{nM} ; \mathrm{p}<0.002)$. Although the mean levels of CHP-EPs (shown in Figure 5C and Table 1) detected in plasma from hospitalized SCD patients (22.9 $\pm 7.5 \mathrm{nM}, \mathrm{n}=5)$ was lower than in plasma from SCD clinic patients $(29.1 \pm 15.1 \mathrm{nM}, \mathrm{n}=6$ patients) the difference is not statistically significantly (NS). As shown in Figure 5D and Table 1, PP-EP concentrations in plasma from SCD patients is nearly 4.8-fold higher than its level in plasma samples from SCD patients hospitalized to treat a sickle cell crisis (7.06 \pm 4.05 vs $1.48 \pm 0.92 \mathrm{nM} ; \mathrm{p}<0.05$ ). Nevertheless, levels of CAP-EPs are 4 to 9 fold higher than those of PP-EP. This pilot study demonstrated that massively elevated levels of CAPEPs are present in blood from SCD patients detected during routine clinical monitoring. 


\section{CAP-EPs promote platelet activation}

Thrombosis is an important aspect of the clinical manifestations of SCD that is considered a "hypercoagulable state". 29,30 Vaso-occlusion that is associated with platelet activation $(P<0.01 \text { for CD62P expression and annexin V binding })^{31}$ is the primary source of SCDassociated morbidity and mortality including pain crises, thrombotic strokes, pulmonary complications and leg ulcers. Defining a role for hypercoagulability in SCD requires further understanding of its pathogenesis. In a previous study, CEP-protein and CPP-protein derivatives were shown to promote platelet activation in vitro and accelerate thrombosis in vivo in a TLR9/MyD88 dependent manner by serving as endogenous novel non-canonical ligands for Toll-like receptor 9 (TLR9). ${ }^{32}$ It seemed highly likely that CAP-EPs would exhibit similar receptor-mediated biological activities as found for the corresponding proteins and peptide derivatives. Therefore, using pure samples prepared in vitro by unambiguous chemical synthesis we recently tested and confirmed the hypothesis that CAPEPs activate platelets. ${ }^{33} \mathrm{CAP}-\mathrm{EP}$ accelerated aggregation in gel-filtered human platelets. However, in platelet rich plasma, CAP-EP alone did not induce platelet aggregation at concentrations used, likely due to sequestration into lipoproteins (VLDL, LDL, HDL) that are present in PRP. However, it promoted platelet hyper-reactivity as evidenced by the accelerated and irreversible aggregation in response to a low dose of the physiological and pathological platelet agonist ADP that is released upon lysis of sickled erythrocytes. ${ }^{34}$ ADP binds to platelet surface ADP receptors amplifying platelet activation and recruiting adjacent platelets.

Under in vitro conditions, platelets from steady-state SCD individuals exhibit significantly greater adhesion to fibrinogen than control platelets. ${ }^{35}$ Participation of the platelet integrin $a_{\text {IIb }} \beta_{3}$ activation in this adhesion was implicated by a significant decrease caused by the $a_{\text {IIb }} \beta_{3}$-function inhibiting antibody PAC-1. P-selectin expression and presentation of activated $\alpha_{I I b} \beta_{3}$ is significantly increased on the surface of SCD platelets compared to healthy control platelets. ${ }^{36}$ In our recent study, CAP-phosphatidylethanolamines were shown to bind directly to TLR2 and, at submicromolar concentrations, induce platelet integrin $a_{\text {IIb }} \beta_{3}$ activation and P-selectin expression in isolated human platelets in a TLR2 dependent manner. ${ }^{33}$

Paradoxically, the percentage of circulating platelets positive for activated integrin $\alpha_{I I b} \beta_{3}$ $(8.8 \pm 1.1)$ is lower in adolescent SCD patients without pain or recent vasoocclusive events compared to healthy controls $(27.1 \pm 5.8, \mathrm{P}<0.01) .{ }^{37}$ Interpretation of this observation is complicated by the depletion of activated platelets owing to the formation of high circulating levels of platelet-monocyte and platelet-neutrophil aggregates in SCD blood. The percent of monocytes with adherent platelets and the percent of neutrophils with adherent platelets in blood from these patients with SCD $(78.7 \pm 4.7$ and $55.7 \pm 5.2 \%$, respectively) were $\sim 4$-fold greater than the percent platelet-monocyte and platelet-neutrophil aggregates in blood from healthy subjects $\left(22.9 \pm 2.4\right.$ and $12.3 \pm 1.3 \%$, respectively, $\mathrm{p}<0.01$ for both). ${ }^{37}$

\section{CAP-EPs promote angiogenesis}

Angiogenesis is under tight regulation in most healthy tissues and is most probably controlled by the balance between proangiogenic and anti-angiogenic factors. ${ }^{38}$ The 
disruption of this balance potentially impacts sickle disease pathobiology. ${ }^{38,} 39$

Overproduction of growth factors such as VEGF in patients with SCD compared to production in healthy patients induces a compensatory increase in neovascularization to overcome the vaso-occlusive crisis. ${ }^{40}$ The abnormal angiogenesis induced by elevated basal VEGF levels in SCD contributes to the development of pulmonary hypertension, proliferative retinopathy, Moyamoya vasculopathy and leg ulcers in SCD. ${ }^{41}$ In addition to excessive VEGF production, elevated levels of CEP-EP and CPP-EP derivatives in SCD can also promote abnormal angiogenesis and contribute to these conditions. Since CEP-EP and CPP-EP derivatives promote angiogenesis in a TLR2-dependent manner that is independent of VEGF/VEGFR2 signaling, ${ }^{16,21}$ elevated levels of these CAP-EPs can promote neovascularization in response to the vaso-occlusive crisis in SCD synergistically with other growth factors such as VEGF. Therefore, it is anticipated that excessive CAP-EP generation plays a role in various aspects of the endothelial pathophysiology of SCD. Just as VEGFdriven angiogenesis is recognized to be an attractive therapeutic target for SCD treatment, and because CAP-EPs promote angiogenesis that is independent of VEGF expression, ${ }^{16,} 42$ the elevated levels of CAP-EPs in SCD suggest another opportunity for novel therapeutic approaches that target $\mathrm{CEP} / \mathrm{CPP}$-driven angiogenesis especially in SCD patients resistant to anti-VEGF therapy.

Elevated levels of CAP-EP will be accompanied by elevated levels of CAP-protein modifications because CAP-protein and CAP-EP modifications are coproduced through competing reactions of common products of lipid oxidation (Scheme 1). Consequently, CAP-EPs found in SCD blood possibly have biological significance for the pathology of SCD not only because nanomolar concentrations of CAP-EPs promote platelet activation and angiogenesis, but because they are indicative of elevated levels of CAP-protein modifications that also promote platelet activation and angiogenesis.

\section{CONCLUSIONS}

In the present study, a series of authentic samples and deuterium labeled internal standards were prepared and an LC-MS/MS assay was developed by measuring levels of CAP- and PP-ETN released through hydrolysis of lipid extracts under catalysis by PLD from

Strdptomyces chromofuscus. In vitro experiments demonstrated that pyrrole derivatives of EPs are substrates of this PLD. The new LC-MS/MS method conveniently provides complementary data on a panel of markers of oxidative injury, i.e., CAP-EPs and PP-EPs, in a single analysis. Because CAP-EPs are biologically active endogenous TLR2/TLR1 ligands that promote platelet activation, it is likely that the elevated levels found in SCD blood promote the prothrombotic phenotype that contributes to the pain and pathogenesis of the disease. Consequently, levels of CAP-EP not only serve as markers of oxidative injury, but may prove useful for guiding potential therapeutic interventions such as the use of anti-CAP antibodies as decoy receptors to modulate CAP-induced angiogenesis or platelet activation.

The new analytical method was successfully applied for simultaneous measurement of both CAP and PP EP derivatives in human blood samples from SCD patients. A small pilot study revealed that levels of CAP-EPs and PP-EPs are significantly elevated in plasma samples from SCD clinic patients compared to those of hospitalized SCD patients. The elevations are 
greater than those observed previously for CEP-EPs in blood from individuals with agerelated macular degeneration. Levels in blood drawn from hospitalized SCD patients were lower, but not as low as levels detected in blood from the healthy controls from the AMD study. The levels of CEP-EPs and CPP-EPs are strongly associated with SCD and may act as biomarkers for detecting SCD severity. Furthermore, CEP associated with SCD and may act as a biomarker for detecting SCD severity. Also, since CEPs and CPPs are biologically active the elevated levels found in SCD blood may have biological significance for the pathology of SCD.

The present observations provide new insights into the hypercoagulable state and the pathogenesis of vaso-occlusive events in SCD. They suggest new directions for clinical management of SCD patients besides the antiplatelet and anticoagulation treatments previously under investigation. The elevated levels of CAP-EP derivatives that we detected in SCD blood can contribute to the generation of a permanent condition of hypercoagulability causing thrombosis and thereby play an essential role in vaso-occlusive events, a critical pathophysiologic feature of SCD. The ability of CAP-EP to induce a native immunity-signaling cascade in platelets that promotes platelet activation, the prothrombotic and angiogenic effects of elevated levels of these endogenous TLR2/TLR1 ligands may provide new mechanism-based targets for developing therapeutic measures to combat the prothrombotic state associated with SCD pathology. Therapies that block the CAPdependent signaling cascade leading to platelet activation can complement antiplatelet therapies, such as glycoprotein IIb/IIIa inhibitors (abciximab, eptifibatide, tirofiban, roxifiban, and orbofiban), which also appear to have anti adhesion effects ${ }^{43}$, or ADPreceptor antagonists (ticlopidine, clopidogrel, prasugrel, and ticagrelor) for ameliorating the vaso-occlusive complications of sickle cell disease.

\section{Supplementary Material}

Refer to Web version on PubMed Central for supplementary material.

\section{Acknowledgments}

Funding Sources

This work was supported by NIH Grants EY016813 and GM021249 to RGS.

\section{ABBREVIATIONS}

AA

AMD

CAP

CEP

CEP-ETN-d 4 arachidonic acid

age-related macular degeneration

2-( $\omega$-carboxyalkyl)pyrrole

2-( $\omega$-carboxyethyl)pyrrole

3-(1-(2-hydroxy-1,1,2,2-D,D,D,D-ethyl)-1H-pyrrol-2-

yl)propanoic acid 


\begin{tabular}{|c|c|}
\hline CHP-ETN-d 4 & $\begin{array}{l}\text { 4-(1-(2-hydroxyethyl-1,1,2,2-d } 4 \text { )-1H-pyrrol-2-yl)butanoic } \\
\text { acid; 8-(1-(2-hydroxyethyl)-1H-pyrrol-2-yl)octanoic acid }\end{array}$ \\
\hline CID & collision-induced dissociation \\
\hline CPP & 2-( $\omega$-carboxypropyl)pyrrole \\
\hline CPP-ETN-d 4 & $\begin{array}{l}\text { 4-(1-(2-hydroxyethyl-1,1,2,2-d } 4 \text { )-1H-pyrrol-2-yl)butanoic } \\
\text { acid }\end{array}$ \\
\hline DHA & docosahexaenoic acid \\
\hline DHA-PC & $\begin{array}{l}\text { 1-palmityl-2-docosahexaenoyl-sn-glycero-3- } \\
\text { phosphocholine }\end{array}$ \\
\hline DODA & $\begin{array}{l}\text { 9,12-dioxododecanoic acid, DOHA, 4,6-dioxoheptanoic } \\
\text { acid, DOHA-Fm, 4,7-dioxoheptanoic acid } 9 H \text {-fluoren-9- } \\
\text { ylmethyl ester }\end{array}$ \\
\hline DOOA & 5,8-dioxooctanoic acid \\
\hline DPPE & 1,2-dipalmitoyl-sn-glycero-3-phosphoethanolamine \\
\hline EP & ethanolamine phospholipid \\
\hline ETN & ethanolamine \\
\hline HBSS & Hank's balanced salt solution \\
\hline HODA & 9-hydroxy-12-oxododec-10-enoic acid \\
\hline HOHА & 4-hydroxy-7-oxo-hept-5-eonic acid \\
\hline HOHА-PC & $\begin{array}{l}\text { 1-palmityl-2-(4-hydroxy-7-oxo-5-heptenoyl)-sn-glycero-3- } \\
\text { phosphatidylcholine }\end{array}$ \\
\hline HOOA & 5-hydroxy-8-oxooct-6-enoic acid \\
\hline LA & linoleic acid \\
\hline PLD & phospholipase D, PP, 2-pentylpyrrole \\
\hline PP-ETN & 2-(2-pentyl-1H-pyrrol-1-yl)ethan-1-ol \\
\hline PP-ETN-d 4 & 2-(2-pentyl-1H-pyrrol-1-yl)ethan-1,1,2,2-d 4 -1-ol \\
\hline PUFA & polyunsaturated fatty acid \\
\hline SCD & sickle cell disease \\
\hline SUV & small unilammelar vesicle \\
\hline TLR & Toll-like receptor \\
\hline
\end{tabular}




\section{References}

1. Uchida K. Histidine and lysine as targets of oxidative modification. Amino Acids. 2003; 25:249257. [PubMed: 14661088]

2. Sayre LM, Lin D, Yuan Q, Zhu X, Tang X. Protein adducts generated from products of lipid oxidation: focus on HNE and one. Drug Metab Rev. 2006; 38:651-675. [PubMed: 17145694]

3. Catala A. An overview of lipid peroxidation with emphasis in outer segments of photoreceptors and the chemiluminescence assay. Int J Biochem Cell Biol. 2006; 38:1482-1495. [PubMed: 16621670]

4. Guichardant M, Taibi-Tronche P, Fay LB, Lagarde M. Covalent modifications of aminophospholipids by 4-hydroxynonenal. Free Radicals Biol Med. 1998; 25:1049-1056.

5. Bernoud-Hubac N, Fay LB, Armarnath V, Guichardant M, Bacot S, Davies SS, Roberts LJ 2nd, Lagarde M. Covalent binding of isoketals to ethanolamine phospholipids. Free Radicals Biol Med. 2004; 37:1604-1611.

6. Kaur K, Salomon RG, O’Neil J, Hoff HF. (Carboxyalkyl)pyrroles in human plasma and oxidized low-density lipoproteins. Chem Res Toxicol. 1997; 10:1387-1396. [PubMed: 9437530]

7. Choi J, Zhang W, Gu X, Chen X, Hong L, Laird JM, Salomon RG. Lysophosphatidylcholine is generated by spontaneous deacylation of oxidized phospholipids. Chem Res Toxicol. 2011; 24:111118. [PubMed: 20973507]

8. Salomon RG, Gu X. Critical insights into cardiovascular disease from basic research on the oxidation of phospholipids: the gamma-hydroxyalkenal phospholipid hypothesis. Chem Res Toxicol. 2011; 24:1791-1802. [PubMed: 21870852]

9. Bacot S, Bernoud-Hubac N, Baddas N, Chantegrel B, Deshayes C, Doutheau A, Lagarde M, Guichardant M. Covalent binding of hydroxy-alkenals 4-HDDE, 4-HHE, and 4-HNE to ethanolamine phospholipid subclasses. J Lipid Res. 2003; 44:917-926. [PubMed: 12588949]

10. Sayre LM, Sha W, Xu G, Kaur K, Nadkarni D, Subbanagounder G, Salomon RG. Immunochemical evidence supporting 2-pentylpyrrole formation on proteins exposed to 4hydroxy-2-nonenal. Chem Res Toxicol. 1996; 9:1194-1201. [PubMed: 8902276]

11. Salomon RG, Kaur K, Podrez E, Hoff HF, Krushinsky AV, Sayre LM. HNE-derived 2pentylpyrroles are generated during oxidation of LDL, are more prevalent in blood plasma from patients with renal disease or atherosclerosis, and are present in atherosclerotic plaques. Chem Res Toxicol. 2000; 13:557-564. [PubMed: 10898587]

12. Salomon RG, Hong L, Hollyfield JG. Discovery of carboxyethylpyrroles (CEPs): critical insights into AMD, autism, cancer, and wound healing from basic research on the chemistry of oxidized phospholipids. Chem Res Toxicol. 2011; 24:1803-1816. [PubMed: 21875030]

13. Gu X, Meer SG, Miyagi M, Rayborn ME, Hollyfield JG, Crabb JW, Salomon RG. Carboxyethylpyrrole protein adducts and autoantibodies, biomarkers for age-related macular degeneration. J Biol Chem. 2003; 278:42027-42035. [PubMed: 12923198]

14. Crabb JW, Miyagi M, Gu X, Shadrach K, West KA, Sakaguchi H, Kamei M, Hasan A, Yan L, Rayborn ME, Salomon RG, Hollyfield JG. Drusen proteome analysis: an approach to the etiology of age-related macular degeneration. Proc Natl Acad Sci U S A. 2002; 99:14682-14687. [PubMed: 12391305]

15. Ebrahem Q, Renganathan K, Sears J, Vasanji A, Gu X, Lu L, Salomon RG, Crabb JW, Anand-Apte B. Carboxyethylpyrrole oxidative protein modifications stimulate neovascularization: Implications for age-related macular degeneration. Proc Natl Acad Sci U S A. 2006; 103:13480-13484. [PubMed: 16938854]

16. West XZ, Malinin NL, Merkulova AA, Tischenko M, Kerr BA, Borden EC, Podrez EA, Salomon RG, Byzova TV. Oxidative stress induces angiogenesis by activating TLR2 with novel endogenous ligands. Nature. 2010; 467:972-976. [PubMed: 20927103]

17. Vance JE, Tasseva G. Formation and function of phosphatidylserine and phosphatidylethanolamine in mammalian cells. Biochim Biophys Acta. 2013; 1831:543-554. [PubMed: 22960354]

18. Li W, Laird JM, Lu L, Roychowdhury S, Nagy LE, Zhou R, Crabb JW, Salomon RG. Isolevuglandins covalently modify phosphatidylethanolamines in vivo: detection and quantitative analysis of hydroxylactam adducts. Free Radicals Biol Med. 2009; 47:1539-1552. 
19. Zemski Berry KA, Murphy RC. Characterization of acrolein-glycerophosphoethanolamine lipid adducts using electrospray mass spectrometry. Chem Res Toxicol. 2007; 20:1342-1351. [PubMed: 17636891]

20. Guo L, Chen Z, Cox BE, Amarnath V, Epand RF, Epand RM, Davies SS. Phosphatidylethanolamines modified by gamma-ketoaldehyde (gammaKA) induce endoplasmic reticulum stress and endothelial activation. J Biol Chem. 2011; 286:18170-18180. [PubMed: 21454544]

21. Wang H, Guo J, West XZ, Bid HK, Lu L, Hong L, Jang GF, Zhang L, Crabb JW, Linetsky M, Salomon RG. Detection and biological activities of carboxyethylpyrrole ethanolamine phospholipids (CEP-EPs). Chem Res Toxicol. 2014; 27:2015-2022. [PubMed: 25380349]

22. Sullivan CB, Matafonova E, Roberts LJ 2nd, Amarnath V, Davies SS. Isoketals form cytotoxic phosphatidylethanolamine adducts in cells. J Lipid Res. 2010; 51:999-1009. [PubMed: 19965577]

23. Lu L, Gu X, Hong L, Laird J, Jaffe K, Choi J, Crabb J, Salomon RG. Synthesis and structural characterization of carboxyethylpyrrole-modified proteins: mediators of age-related macular degeneration. Bioorg Med Chem. 2009; 17:7548-7561. [PubMed: 19786352]

24. Globisch M, Kaden D, Henle T. 4-Hydroxy-2-nonenal (4-HNE) and Its Lipation Product 2Pentylpyrrole Lysine (2-PPL) in Peanuts. J Agric Food Chem. 2015; 63:5273-5281. [PubMed: 25945920]

25. Nur E, Biemond BJ, Otten HM, Brandjes DP, Schnog JJ. Oxidative stress in sickle cell disease; pathophysiology and potential implications for disease management. Amer J Hematol. 2011; 86:484-489. [PubMed: 21544855]

26. Chirico EN, Pialoux V. Role of oxidative stress in the pathogenesis of sickle cell disease. IUBMB life. 2012; 64:72-80. [PubMed: 22131167]

27. Akohoue SA, Shankar S, Milne GL, Morrow J, Chen KY, Ajayi WU, Buchowski MS. Energy expenditure, inflammation, and oxidative stress in steady-state adolescents with sickle cell anemia. Pediatric Res. 2007; 61:233-238.

28. Wood KC, Granger DN. Sickle cell disease: role of reactive oxygen and nitrogen metabolites. Clin Exp Pharmacol Physiol. 2007; 34:926-932. [PubMed: 17645642]

29. Francis RB Jr. Platelets, coagulation, and fibrinolysis in sickle cell disease: their possible role in vascular occlusion. Blood Coagulation Fibrinolysis. 1991; 2:341-353. [PubMed: 1893065]

30. De Franceschi L, Cappellini MD, Olivieri O. Thrombosis and sickle cell disease. Semin Thromb Hemost. 2011; 37:226-236. [PubMed: 21455857]

31. Tomer A, Harker LA, Kasey S, Eckman JR. Thrombogenesis in sickle cell disease. J Lab Clin Med. 2001; 137:398-407. [PubMed: 11385360]

32. Panigrahi S, Ma Y, Hong L, Gao D, West XZ, Salomon RG, Byzova TV, Podrez EA. Engagement of platelet toll-like receptor 9 by novel endogenous ligands promotes platelet hyperreactivity and thrombosis. Circ Res. 2013; 112:103-112. [PubMed: 23071157]

33. Biswas S, Xin L, Panigrahi S, Zimman A, Wang H, Yakubenko V, Byzova TV, Salomon RG, Podrez EA. Novel phosphatidylethanolamine derivatives accumulate in circulation in hyperlipidemic ApoE-/- mice and activate platelets via TLR2. Blood. 2016; 127:2618-29. [PubMed: 27015965]

34. Gaarder A, Jonsen J, Laland S, Hellem A, Owren PA. Adenosine diphosphate in red cells as a factor in the adhesiveness of human blood platelets. Nature. 1961; 192:531-532. [PubMed: 13896038]

35. Proenca-Ferreira R, Franco-Penteado CF, Traina F, Saad ST, Costa FF, Conran N. Increased adhesive properties of platelets in sickle cell disease: roles for alphaIIb beta3-mediated ligand binding, diminished cAMP signalling and increased phosphodiesterase $3 \mathrm{~A}$ activity. Br J Haematol. 2010; 149:280-288. [PubMed: 20136824]

36. Villagra J, Shiva S, Hunter LA, Machado RF, Gladwin MT, Kato GJ. Platelet activation in patients with sickle disease, hemolysis-associated pulmonary hypertension, and nitric oxide scavenging by cell-free hemoglobin. Blood. 2007; 110:2166-2172. [PubMed: 17536019]

37. Frelinger AL 3rd, Jakubowski JA, Brooks JK, Carmichael SL, Berny-Lang MA, Barnard MR, Heeney MM, Michelson AD. Platelet activation and inhibition in sickle cell disease (pains) study. Platelets. 2014; 25:27-35. [PubMed: 23469943] 
38. Kim SY, Mocanu C, McLeod DS, Bhutto IA, Merges C, Eid M, Tong P, Lutty GA. Expression of pigment epithelium-derived factor (PEDF) and vascular endothelial growth factor (VEGF) in sickle cell retina and choroid. Exp Eye Res. 2003; 77:433-445. [PubMed: 12957143]

39. Solovey A, Gui LZ, Ramakrishnan S, Steinberg MH, Hebbel RP. Sickle cell anemia as a possible state of enhanced anti-apoptotic tone: Survival effect of vascular endothelial growth factor on circulating and unanchored endothelial cells. Blood. 1999; 93:3824-3830. [PubMed: 10339489]

40. Qari MH, Dier U, Mousa SA. Biomarkers of inflammation, growth factor, and coagulation activation in patients with sickle cell disease. Clin Appl Thromb Hemost. 2012; 18:195-200. [PubMed: 21949038]

41. Duits AJ, Rodriguez T, Schnog JJ. Serum levels of angiogenic factors indicate a pro-angiogenic state in adults with sickle cell disease. Br J Haematol. 2006; 134:116-119. [PubMed: 16803577]

42. Gurkan E, Tanriverdi K, Baslamisli F. Clinical relevance of vascular endothelial growth factor levels in sickle cell disease. Ann Hematol. 2005; 84:71-75. [PubMed: 15322765]

43. Kaul DK, Tsai HM, Liu XD, Nakada MT, Nagel RL, Coller BS. Monoclonal antibodies to alphaVbeta3 (7E3 and LM609) inhibit sickle red blood cell-endothelium interactions induced by platelet-activating factor. Blood. 2000; 95:368-374. [PubMed: 10627437] 

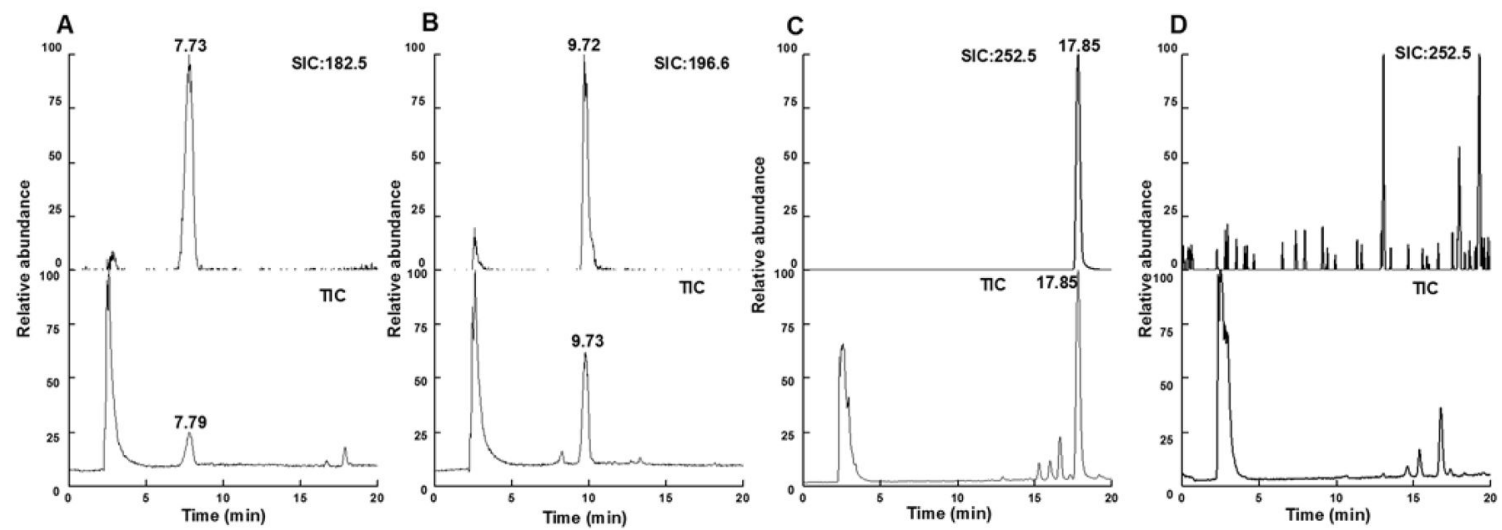

Figure 1.

LC-MS data supports the conclusion that PLD from Streptomyces chromofuscus catalyzes the hydrolysis of CAP-DPPE to deliver the corresponding CAP-ETN. CAP-DPPE standards were treated either with or without PLD overnight. Then CAP-ETN was analyzed by LCMS in the negative ion model. (A) CEP-DPPE plus PLD. (B) CPP-DPPE plus PLD. (C) CHP-DPPE plus PLD. (D) CHP-DPPE without PLD. Top traces: selected ion chromatograms (SICs) of CEP-ETN (m/z 182.5), CPP-ETN (m/z 196.6) and CHP-ETN (m/z $252.5)$ detected in the reaction mixture in the negative ion mode. Bottom traces: total ion chromatograms of the reaction mixtures. 


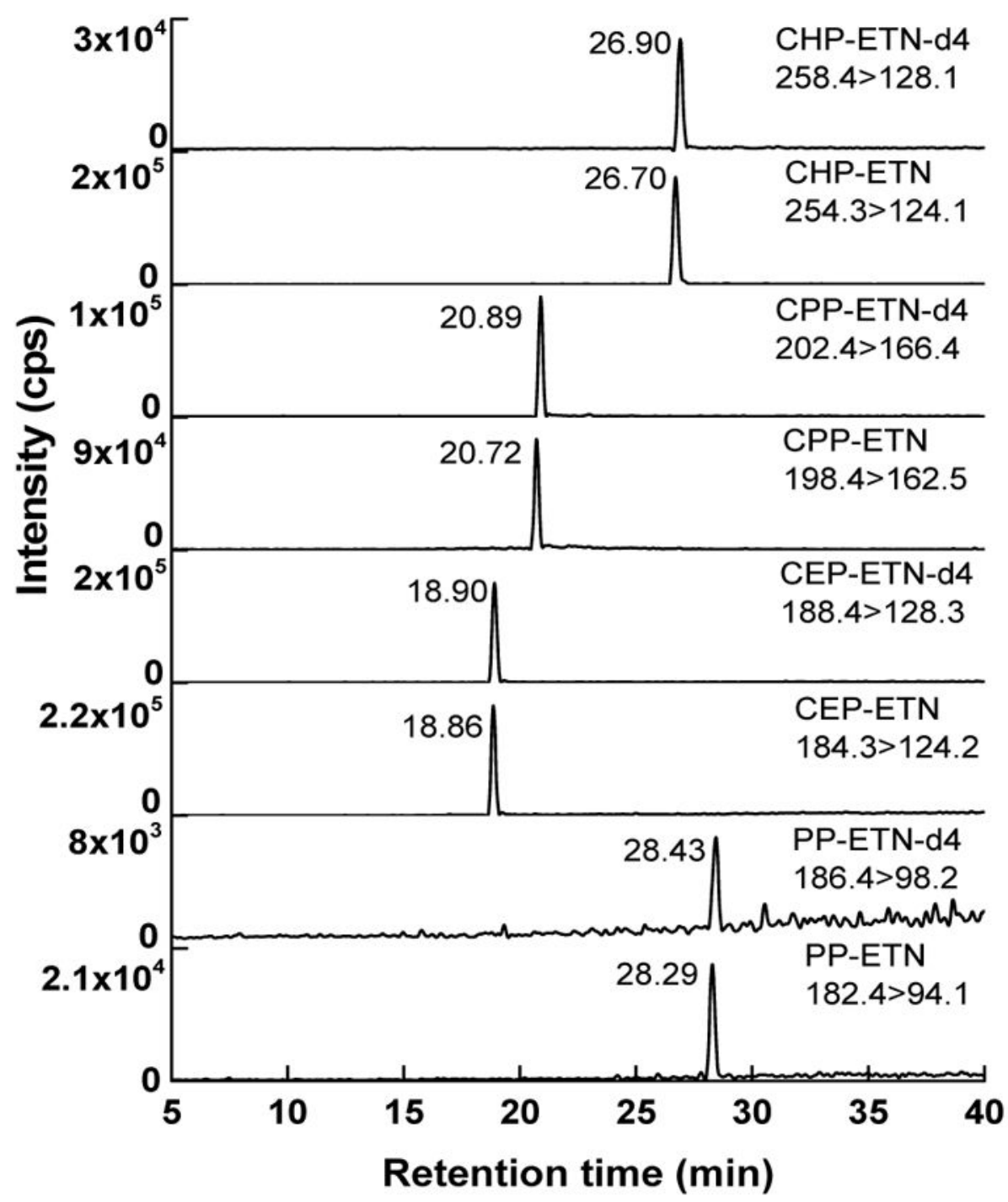

Figure 2.

MRM chromatographs from LC/MS/MS analysis of a mixture of all eight authentic standards (CEP-ETN, CEP-ETN-d ${ }_{4}$, CPP-ETN, CPP-ETN-d ${ }_{4}$, CHP-ETN, CHP-ETN- $\mathrm{d}_{4}$, PP-ETN and PP-ETN- $\mathrm{d}_{4}$ ) in the positive ion mode using $0.1 \%$ formic acid as additive. 


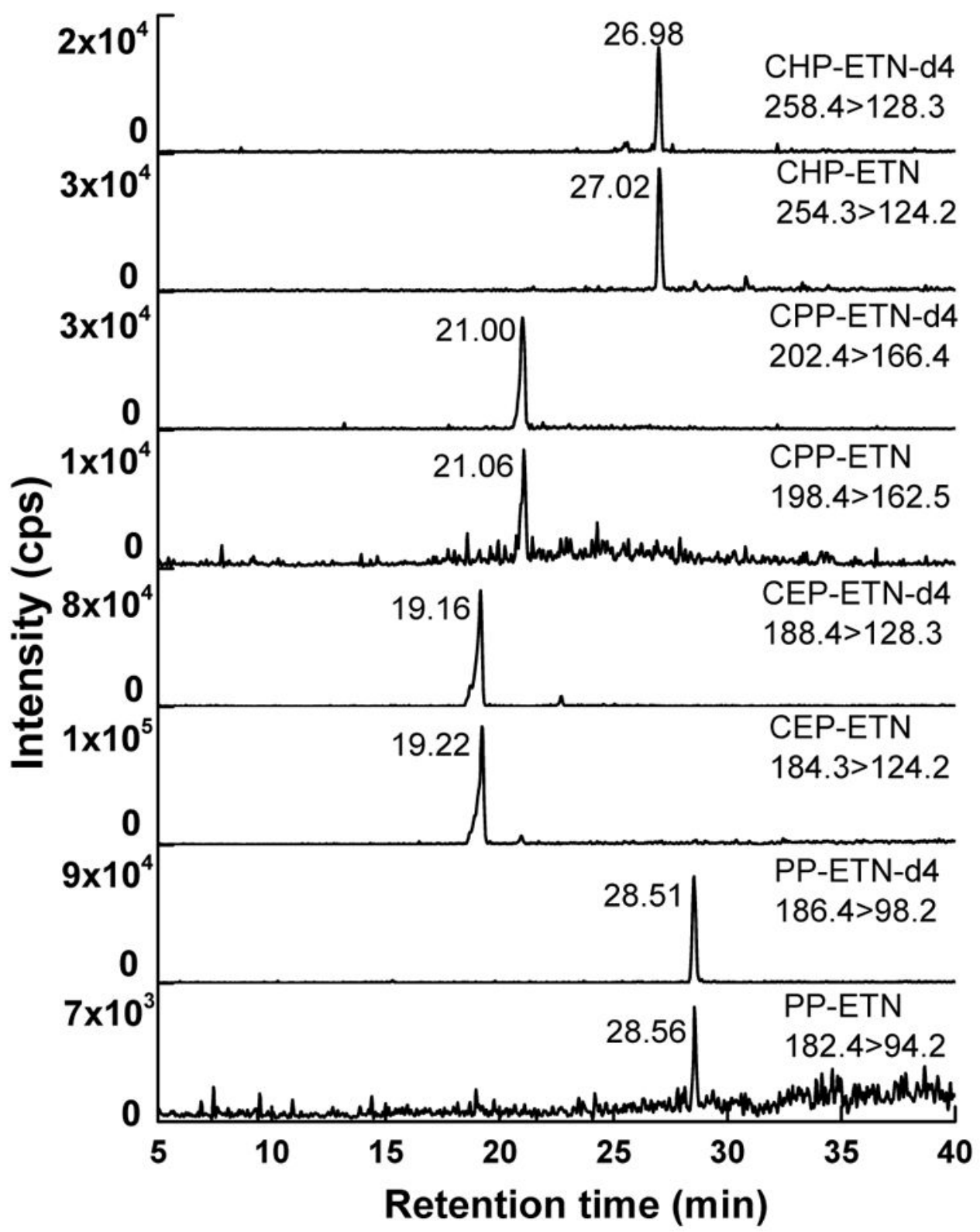

Figure 3.

Representative LC-MS/MS chromatograms of CAP-ETN and PP-ETN generated by PLD hydrolysis of phospholipids extracted from human blood plasma samples from hospitalized patients with SCD. 


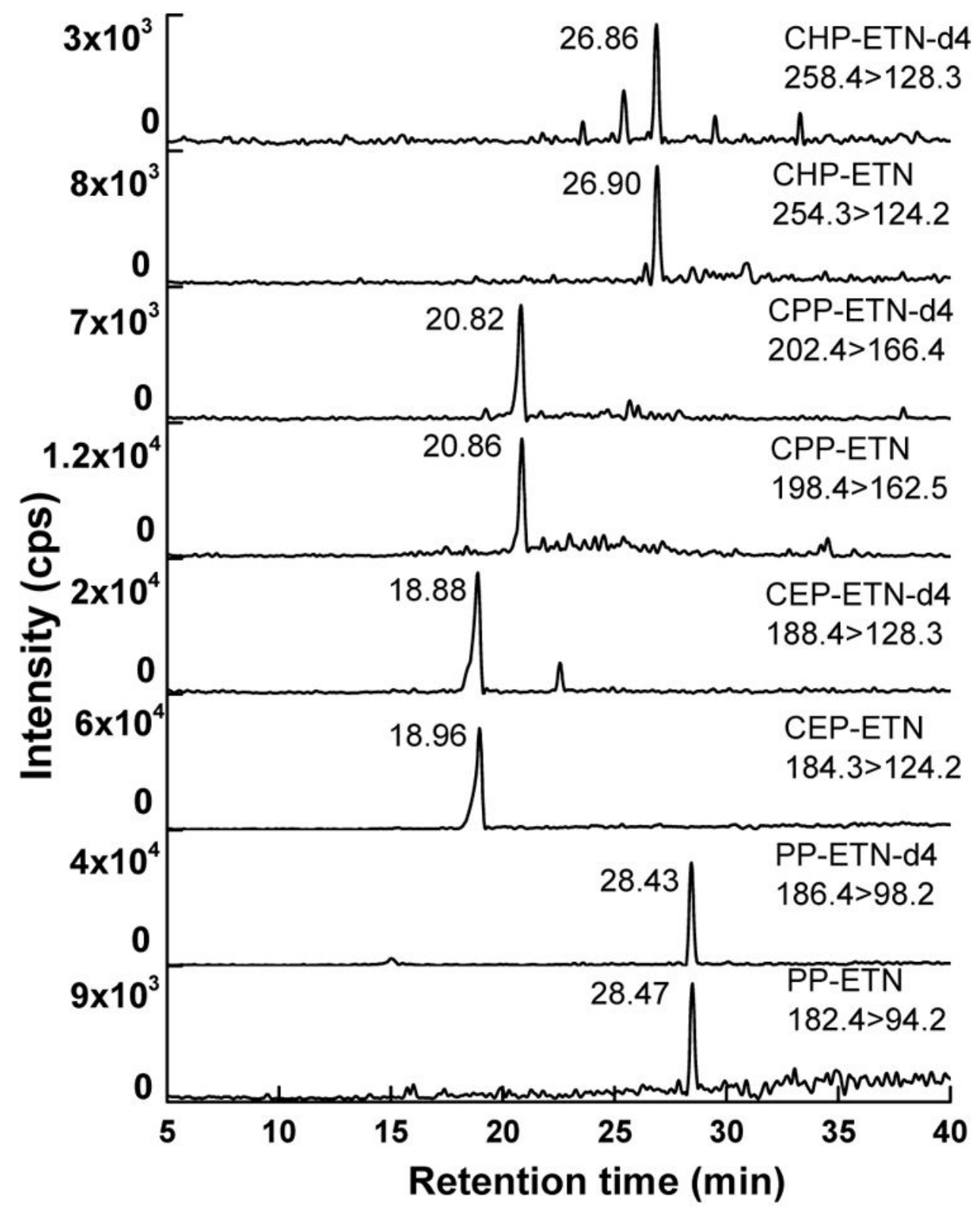

Figure 4.

Representative LC-MS/MS chromatograms of CAP-ETN and PP-ETN generated by PLD hydrolysis of phospholipids extracted from human blood plasma samples from clinic patients with SCD. 

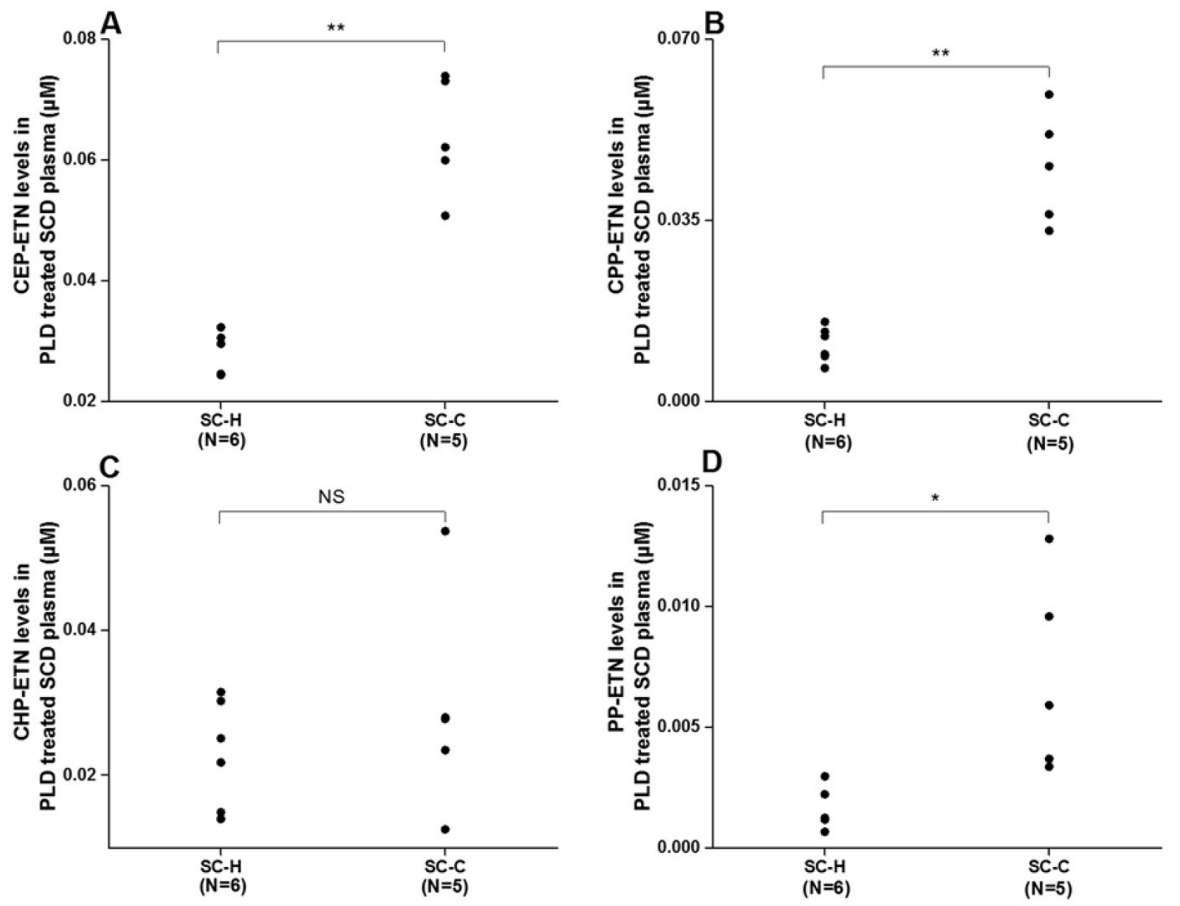

Figure 5.

Levels of pyrroles in human plasma samples from SCD clinic patients $(\mathrm{SC}-\mathrm{C}, \mathrm{n}=5)$ and hospitalized SCD patients (SC-H, $\mathrm{n}=6$ ) determined by LC-MS/MS: (A) CEP-ETN, ** $=\mathrm{p}$ $<0.002$; (B) CPP-ETN, ** $=\mathrm{p}<0.002$; (C) CHP-ETN, "NS"-not significant; (D) PP-ETN, $*=\mathrm{p}<0.05$. 
PUFAs

$\mathrm{R}=$ 2-lysophpspholipid<smiles>[R]OC(=O)CC/C=C\C/C=C\[SbH2]</smiles>
linoleic acid (LA)-PL
$\gamma$-Hydroxy- $\alpha, \beta-$ unsaturated Aldehydes

$\overbrace{\left(\mathrm{CH}_{2}\right)_{7} \mathrm{COOR}}^{\mathrm{OH}}$<smiles>O=C(O)CC/C=C\C=C\C(O)C1CCCCC1</smiles>

HODA-PL

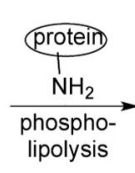

Pyrroles

protein

$\overbrace{\text { CHP }}^{\left(\mathrm{CH}_{2}\right)_{7} \mathrm{COOH}}$
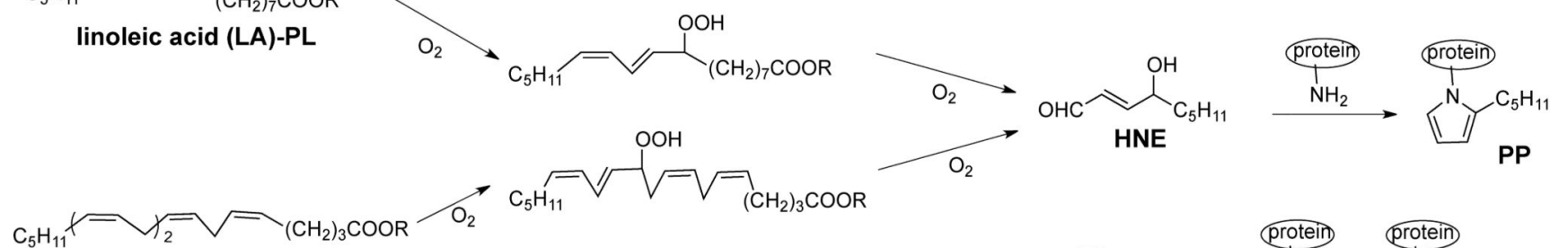

arachidonic acid (AA)-PL

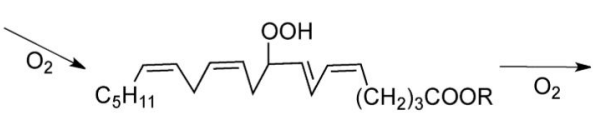

$\overbrace{\left(\mathrm{CH}_{2}\right)_{3} \mathrm{COOR}}^{\mathrm{OH}}$
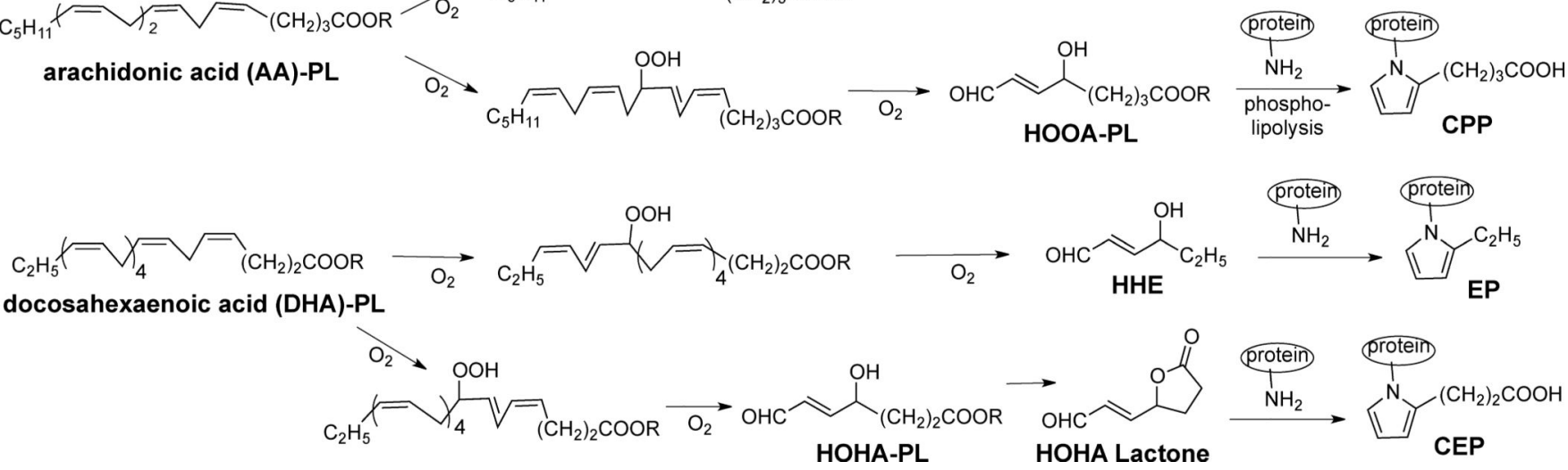

Scheme 1.

$\gamma$-Hydroxyalkenals generated by free radical-initiated oxidation of phospholipids containing PUFAs react with $\varepsilon$-amino groups of protein lysyl residues to produce pyrrole modifications. 


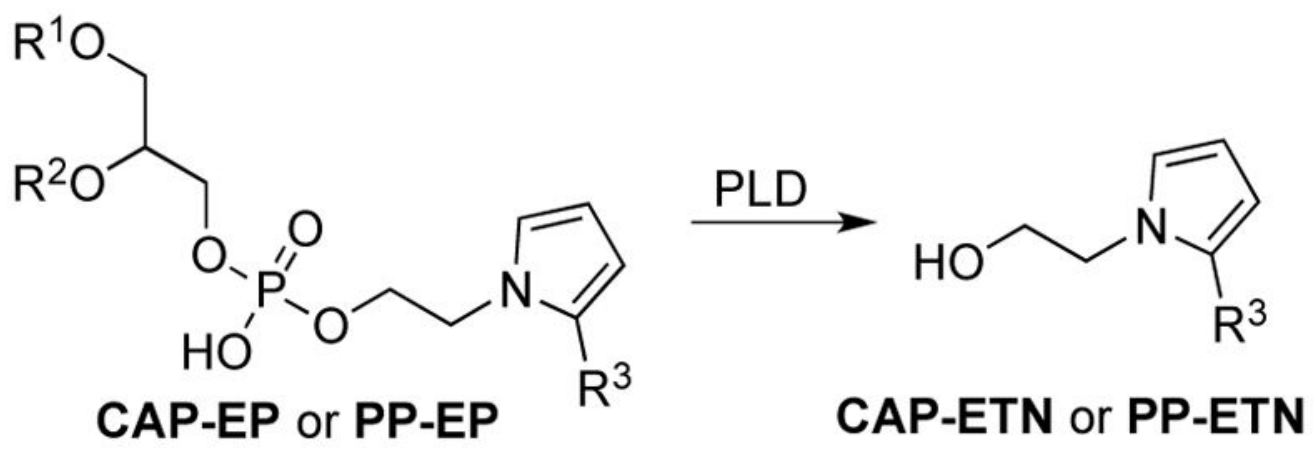

$$
\begin{aligned}
& \mathrm{R}^{1}=\text { alkyl, acyl or vinyl, } \mathrm{R}^{2}=\text { acyl } \\
& \mathrm{R}^{3}=-\left(\mathrm{CH}_{2}\right)_{2} \mathrm{COOH},-\left(\mathrm{CH}_{2}\right)_{3} \mathrm{COOH},-\left(\mathrm{CH}_{2}\right)_{7} \mathrm{COOH} \text { or } \mathrm{C}_{5} \mathrm{H}_{11}
\end{aligned}
$$

Scheme 2.

Hydrolysis of CAP-EPs or PP-EPs catalyzed by PLD delivers CAP-ETN or PP-ETN. 
Biological Sample

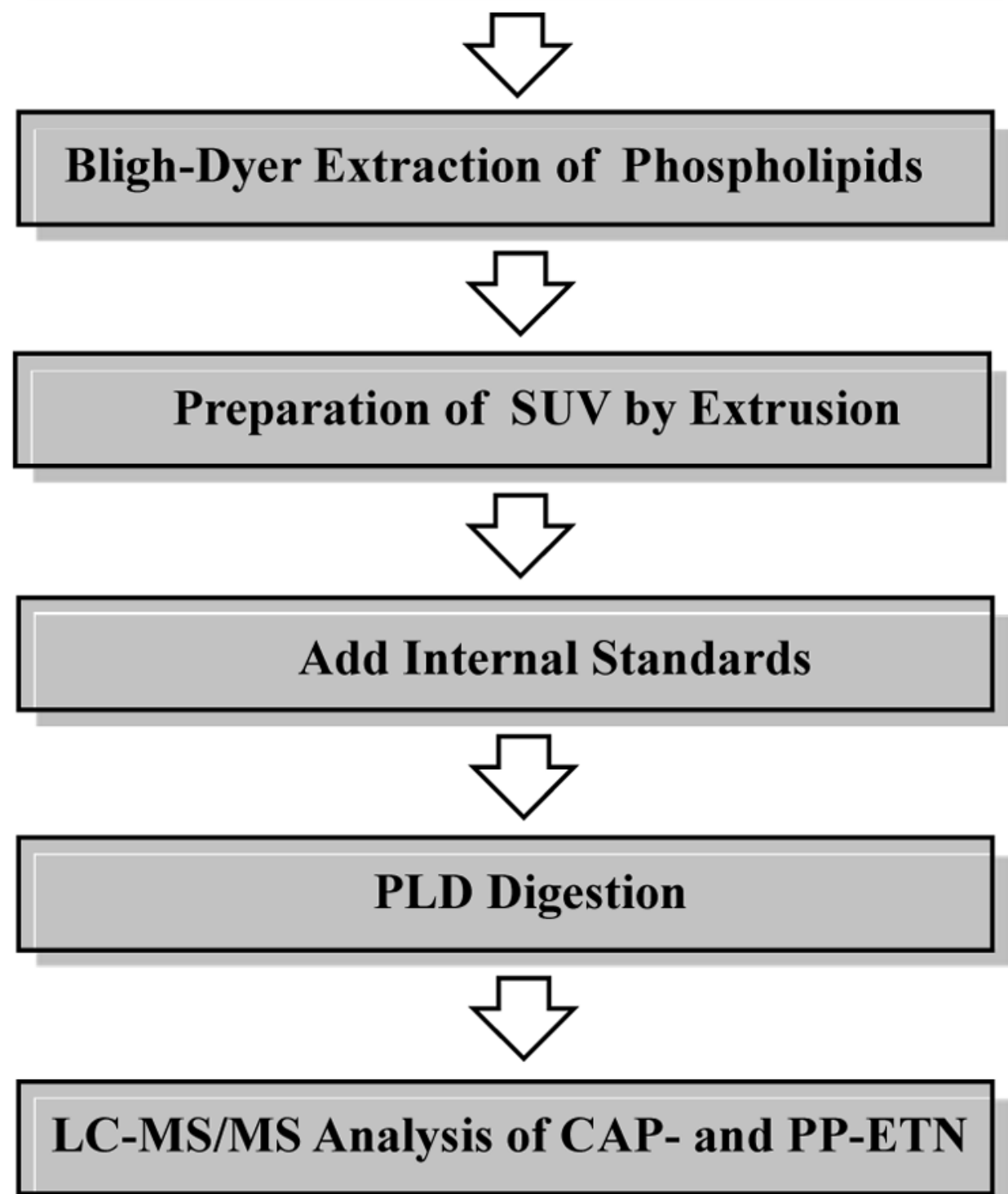

Scheme 3.

Protocol for analysis of CAP- and PP- modified EPs in biological samples. 

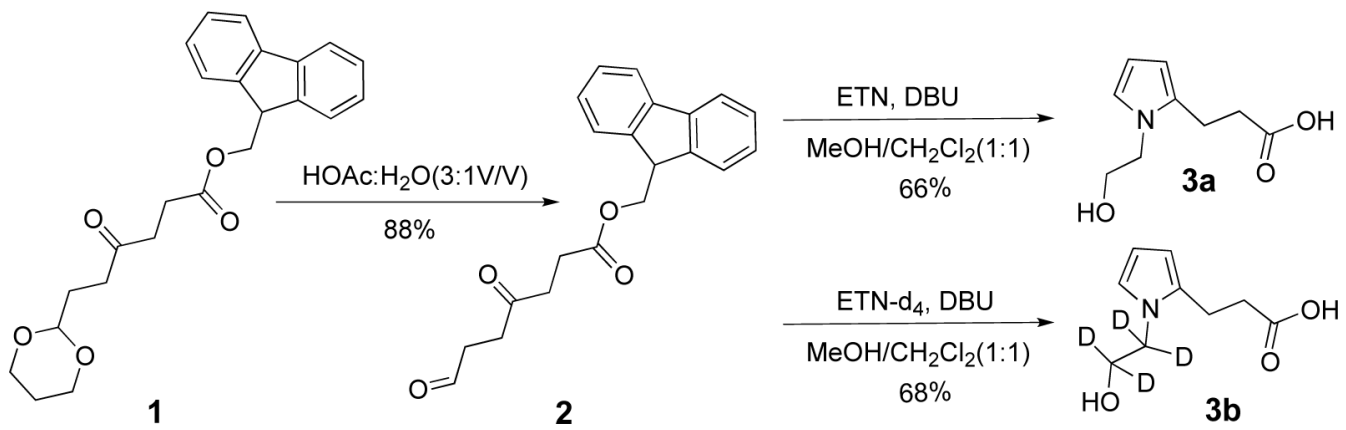

Scheme 4.

Synthesis of CEP derivatives of ETN and deuterated ETN-D 4 . 
<smiles>O=C(O)CCC(=O)NSc1nccs1</smiles><smiles>O=C(O)Cc1cccn1CCO</smiles>

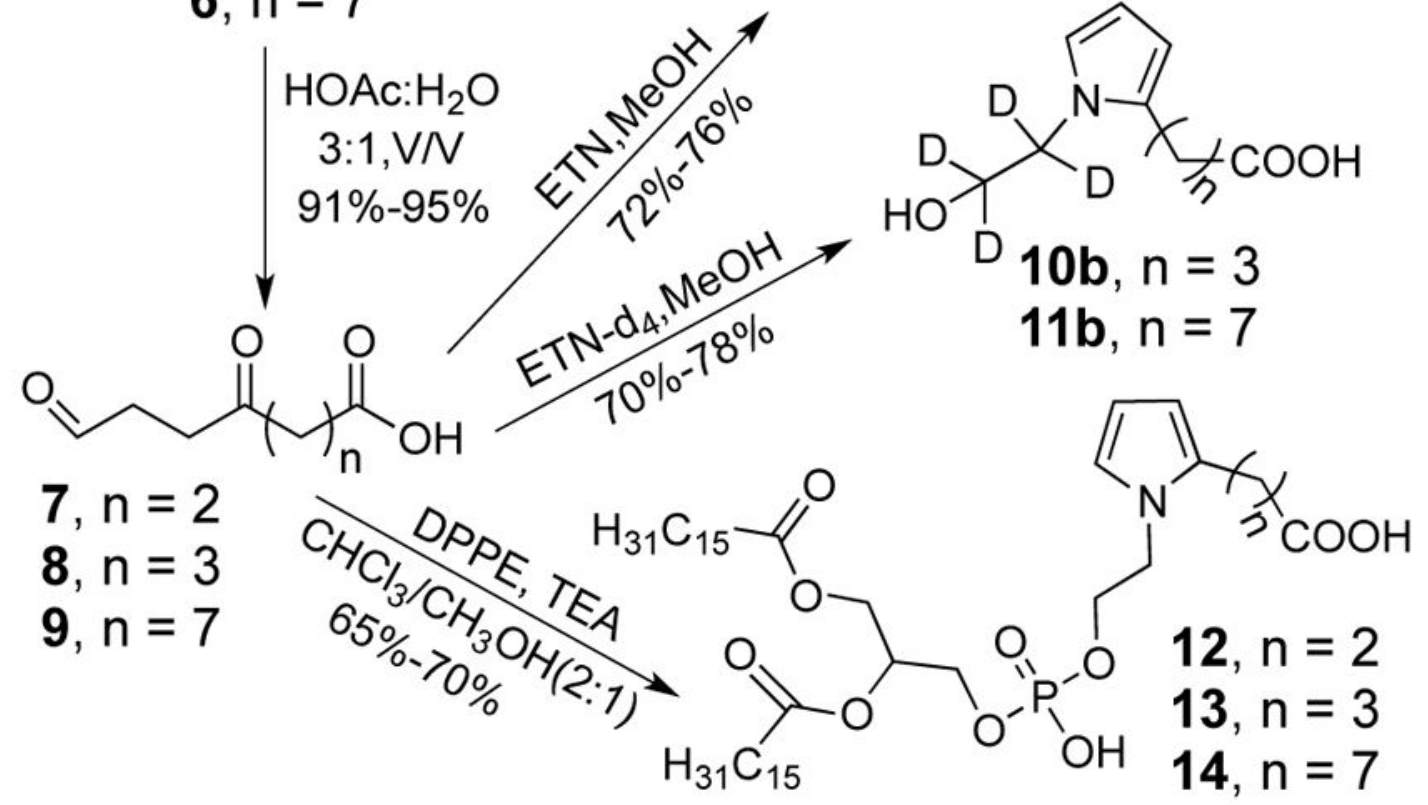

Scheme 5.

Syntheses of CPP, CHP derivatives of ETN and deuterated ETN. 


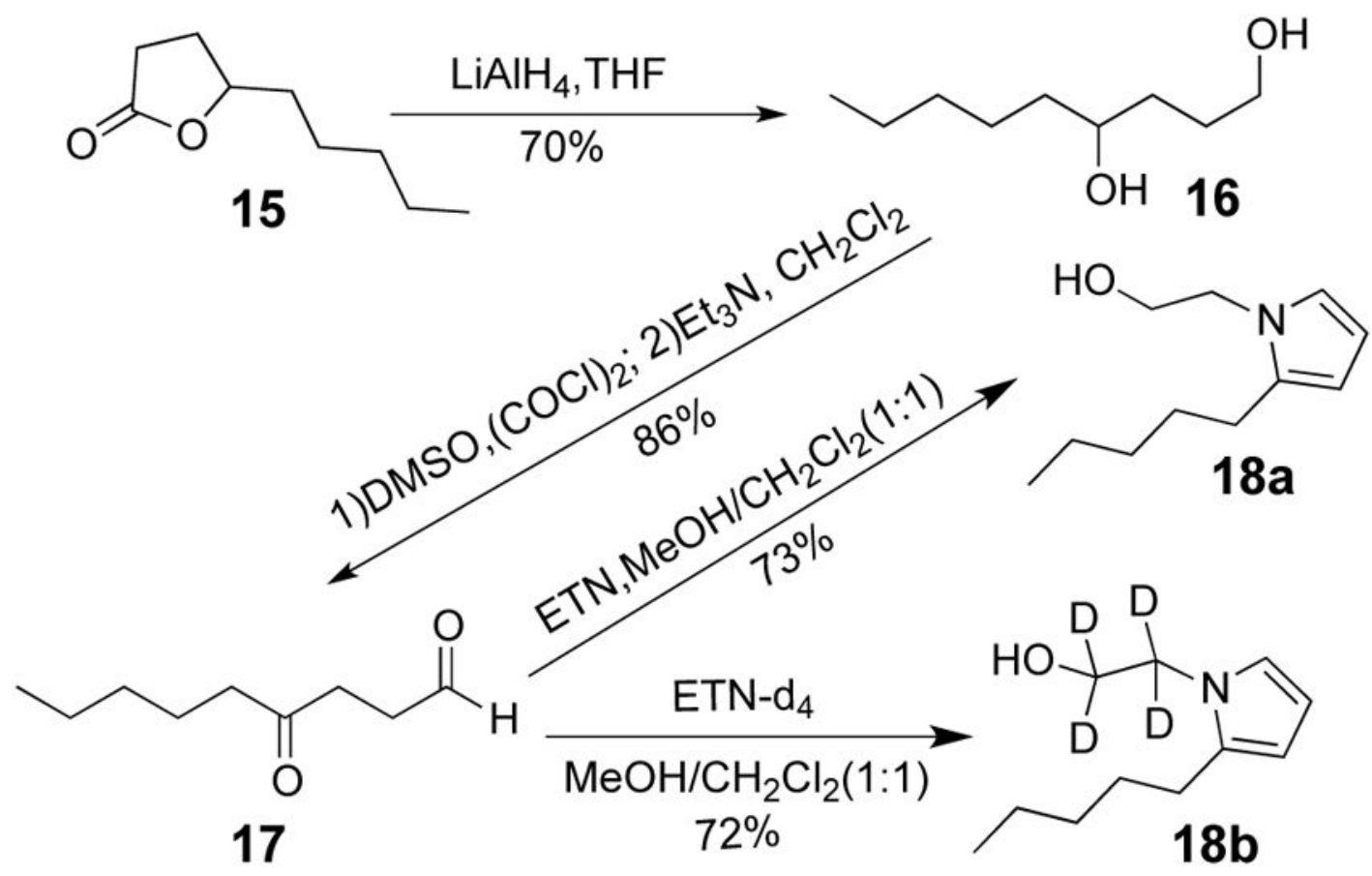

Scheme 6.

Synthesis of PP modified ETN and deuterated ETN as well as DPPE. 


\section{Table 1}

LC-MS/MS analysis of SCD and AMD plasma levels of PP-EP and CAP-EP.

\begin{tabular}{|c|c|c|c|c|}
\hline & PP-EP $(\mathbf{n M})($ mean \pm SD) & CEP-EP $(\mathbf{n M})($ mean \pm SD $)$ & CPP-EP $(\mathbf{n M})($ mean \pm SD $)$ & $\begin{array}{c}\text { CHP-EP }(\mathbf{n M})(\text { mean } \pm \\
\text { SD })\end{array}$ \\
\hline SC-H $(\mathrm{N}=6)$ & $1.48 \pm 0.92$ & $27.6 \pm 3.6$ & $10.9 \pm 3.4$ & $22.9 \pm 7.5$ \\
\hline SC-C $(\mathrm{N}=5)$ & $7.06 \pm 4.05$ & $63.9 \pm 9.7$ & $45.1 \pm 10.9$ & $29.1 \pm 15.1$ \\
\hline AMD $(\mathrm{N}=10)$ & & $56.3 \pm 37.1$ & & \\
\hline Normal $(\mathrm{N}=7)$ & & $12.1 \pm 10.5$ & & \\
\hline
\end{tabular}

